\title{
TOP CITED PAPERS IN INTERNATIONAL PSYCHOGERIATRICS: 2. QUALITY ADJUSTED LIFE YEARS IN OLDER ADULTS WITH DEPRESSIVE SYMPTOMS AND CHRONIC MEDICAL DISORDERS
}

\section{Reflection}

I would like to thank the editor of International Psychogeriatrics for the opportunity to comment on this article (Unützer et al., 2000). The work leading to this paper was undertaken early in my career and has become the foundation for a decade of research focused on improving the care of older adults with depression.

This paper was initially inspired by the work of one of my mentors, Dr. Kenneth Wells, who had published a seminal article that established depression as a major source of disability on a par with other common medical disorders (Wells et al., 1989). Other sources of inspiration came from my mentor, Dr. Wayne Katon, who introduced me to the world of primary care psychiatry and helped me appreciate that while most depressed older adults receive treatment from primary care providers, few of them seek care from a mental health specialist such as a geriatric psychiatrist (Unützer et al., 1999b). Research by other influential investigators early in my career had established high rates of depression in older primary care patients (Schulberg et al., 1998) and poor or ineffective treatment of depression in such patients (Callahan, 2001).

In this context, I set out to examine the impact of depression on older primary care patients. Specifically, I hoped to help put the burden of depression in perspective for primary care providers and policy-makers by comparing it with the burden associated with chronic medical disorders common in late life.

I was fortunate to identify a well-characterized representative data set of community-living older adults who had been prospectively followed with repeated measurements of depression, chronic medical disorders, and health-related quality of life (Patrick et al., 1999) and to have the outstanding support of Dr. Patrick, the principal investigator of the parent study and several experienced colleagues with expertise in clinical epidemiology, health services research, and biostatistics. In addition to documenting the effects of depression on healthrelated quality of life, we were able to show that in this large sample of community-living older adults, depression was associated with significant increases in total health care costs (Unützer et al., 1997) but that few older adults received effective care for depression (Unützer et al., 1999a).

Why has this article become frequently cited? I believe that our paper helped document the substantial public health burden associated with late-life depression and that it called attention to this problem not only from geriatric psychiatrists and other mental health experts but from primary care and other health care providers who were more familiar with other chronic medical disorders in older adults. By comparing the impact of depression with that of other common medical conditions using a representative sample of community-living older adults, we helped to demonstrate that mental health is an important part of overall health in late life.

In the ten years since the publication of this article, our knowledge of late-life depression in primary care has grown substantially. We have important new evidence about the extent and longterm effects of late-life depression in primary care (Cui et al., 2008) and other population-based studies have documented the substantial impact of depression on functioning (Pérès et al., 2007) and active life expectancy (Reynolds et al., 2008) in older adults. Research from several countries has begun to demonstrate important interactions between depression and other chronic medical disorders (Katon, 2003; Moussavi et al., 2007; Pérès et al., 2007).

Our original work on the impact of and quality of care for late-life depression also laid the groundwork for what has become a decade of research on ways to improve care for depressed older adults. In recent years we have seen the development of several evidence-based programs in which primary care providers and mental health specialists collaborate effectively to improve care for late-life depression (Unützer et al., 2002; Bruce et al., 2004). These programs have been found to be effective not only across a range of health care settings but also in patients with and without comorbid medical disorders (Harpole et al., 2005). They have also been found to be more cost-effective than usual care for depressed older adults (Katon et al., 2005) with potential savings in total health care costs over the long run (Unützer et al., 2008a).

While we have made important progress in understanding the impact and treatment of late-life depression in primary care, substantial challenges 
persist. Important structural, policy, and financial barriers must be overcome to allow the widespread implementation of evidence-based collaborative care programs for depression. And while wellimplemented collaborative care programs can more than double the likelihood that a depressed older person experiences a substantial reduction in their depressive symptoms, (Unützer et al., 2002) many participants in trials of collaborative care for late-life depression have persistent depression symptoms despite fairly intensive pharmacologic and nonpharmacologic treatment for depression.

One of the strongest predictors of poor treatment response is the presence of functionally disabling chronic physical pain (Thielke et al., 2007). The combination of emotional pain associated with depression and physical pain often associated with osteoarthritis in older adults seems to be particularly challenging. Interestingly, this finding takes us back to our original paper in which we found that at a population level, arthritis was associated with the greatest losses in quality adjusted life years. The effective treatment of older adults who have combinations of emotional and physical pain creates important new clinical challenges for those of us who are trained as mental health specialists. While most of us would agree with the World Health Organization's definition of health as "a state of complete physical, mental and social well-being and not merely the absence of disease or infirmity," few of us are equipped to address the full range of physical, emotional, and social challenges faced by our older patients.

Integrated models of care in which professionals with different areas of expertise effectively collaborate to care for older adults with depression and other comorbid medical and social challenges are likely to be among the most promising avenues for improving health among older depressed patients. Recent work by Katon and colleagues (2005) demonstrates the feasibility of collaborative care programs that address not only common mental disorders such as depression but also important chronic physical problems such as diabetes or heart disease. We have also recently developed and pilot-tested a promising new program of care management for older primary care patients with depression and functionally disabling physical pain from arthritis. In this program, a nurse care manager working closely with the patient's primary care physician and a consulting geriatric psychiatrist was able to achieve substantial reductions in both depression and physical pain (Unützer et al., 2008b). More work is needed on such combined intervention strategies.

Returning to the original article (Unützer et al., 2000), I would like to share one final "lesson" from this work. The data for this study came from a large randomized controlled trial (RCT) of health prevention for community-living Medicare recipients (Patrick et al. 1999). While well intended and well executed, this large RCT of health prevention strategies for older adults turned out to be a "negative trial." Our paper was a secondary data analysis that was conducted several years after the conclusion of the original study. I point this out to encourage young investigators to seek out and make use of existing data sources for their initial work. If well done, such "secondary analyses" of existing data can make important contributions to science, become frequently cited, and help launch the career of a young investigator, especially if he or she is as fortunate as I was at the time to receive the guidance and technical support from an experienced team of researchers who helped coauthor this paper with me.

\author{
JÜRGEN UNÜTZER \\ Professor and Vice-Chair of Psychiatry and Behavioral \\ Sciences, University of Washington, U.S.A. \\ Email: unutzer@u.washington.edu
}

\section{Commentary}

The quality of this paper, which had received 49 citations by the end of 2006, was recognized even before publication, when it was awarded first place in the 1999 International Psychogeriatric Association (IPA)/Bayer Research Awards in Psychogeriatrics. Prizes are awarded for first, second and third place and are hotly contested, with the 2007 awards having 38 entries (Ames, 2008). Since the inception of these biennial awards, papers that have received the accolade of an award often have been among the highest cited of all papers in International Psychogeriatrics in the years following publication, and indeed, another paper from the same issue of the journal, which won third place in those 1999 awards (Gerdner, 2000), also features among our top-cited papers and will be highlighted in an issue of International Psychogeriatrics later this year.

Depression and dementia form the bread and butter of psychogeriatric work, and the immense burden created by both these disorders has been recognized outside of our specialty only relatively 
recently. The excellent paper of Unützer et al. (2000) was important in showing just what a large impact upon quality of life was created by depressive symptoms in relation to other common medical disorders, which those not exposed to psychiatric practice might intuitively feel to be more burdensome. What was even more important about this paper was that it reported research conducted in a primary care setting. Only a small number of people with depression (usually the most severely affected) ever see a psychiatrist and the bulk of late-life depression is managed in primary care. Again, it might be assumed by some that these cases would be less severe than those treated in psychiatric settings and therefore such depressions might not impact very markedly upon quality of life. That this is not the case was elegantly shown by Unützer et al. (2000). Their study examined a large sample (2558) over a long period (four years) and used robust measures of depression and quality of life as well as reliable diagnostic information in relation to medical conditions. It represents an important piece of evidence confirming the enormous negative impact of depression upon quality of life and thoroughly deserves its status as the second most cited paper in International Psychogeriatrics of all time.

\section{DAVID AMES}

Editor-in-Chief of International Psychogeriatrics

Melbourne, Australia

Email: ipaj-ed@unimelb.edu.au

\section{References}

Ames, D. (2008). The 2007 International Psychogeriatric Association (IPA) research awards in psychogeriatrics. International Psychogeriatrics, 20, 219-220.

Bruce, M. L. et al. (2004). Reducing suicidal ideation and depressive symptoms in depressed older primary care patients: a randomized controlled trial. $\mathcal{F} A M A, 291$, 1081-1091.

Callahan, C. M. (2001). Quality improvement research on late life depression in primary care. Medical Care, 39, 772-784.

Cui, X., Lyness, J. M., Tang, W., Tu, X. and Conwell, Y. (2008). Outcomes and predictors of late-life depression trajectories in older primary care patients. American fournal of Geriatric Psychiatry, 16, 406-415.

Gerdner, L. (2000). Effects of individualized versus classical "relaxation" music on the frequency of agitation in elderly persons with Alzheimer's disease and related disorders. International Psychogeriatrics, 12, 49-65.

Harpole, L. H. et al. (2005). Improving depression outcomes in older adults with comorbid medical illness. General Hospital Psychiatry, 27, 4-12.
Katon, W. J. (2003). Clinical and health services relationships between major depression, depressive symptoms, and general medical illness. Biological Psychiatry, 54, 216226.

Katon, W. et al. (2005). Cost-effectiveness of improving primary care treatment of late-life depression. Archives of General Psychiatry, 62, 1313-1320.

Moussavi, S., Chatterji, S., Verdes, E., Tandon, A., Patel, V. and Ustun, B. (2007). Depression, chronic diseases, and decrements in health: results from the World Health Surveys. Lancet, 370, 851-858.

Patrick, D. L. et al. (1999). Cost and outcomes of Medicare reimbursement for HMO preventive services. Health Care Financing Review, 20, 25-43.

Pérès, K., Jagger, C. and Mathews, F. E. (2007). Impact of late-life self-reported emotional problems on disability-free life expectancy: results from the MRC Cognitive Function and Ageing Study. International fournal of Geriatric Psychiatry, 23, 643-649.

Reynolds, S. L., Haley, W. E. and Kozlenko, N. (2008). The impact of depressive symptoms and chronic diseases on active life expectancy in older Americans. American fournal of Geriatric Psychiatry, 16, 425-432.

Schulberg, H. C., Mulsant, B., Schulz, R., Rollman, B. L., Houck, P. R. and Reynolds, C. F. III. (1998). Characteristics and course of major depression in older primary care patients. International fournal of Psychiatry in Medicine, 28, 421-436.

Thielke, S., Fan, M-Y., Sullivan, $M$ and Unützer, J. (2007). Pain limits the effectiveness of collaborative care for depression. American fournal of Geriatric Psychiatry, 15, 699-707.

Unützer, J. et al. (1997). Depressive symptoms and the cost of health services in HMO patients aged 65 years and older: a 4-year prospective study. $\mathcal{F A M A}, 277,1618-1623$.

Unützer, J. et al. (1999a). Patterns of care for depressed older adults in a large-staff model HMO. American fournal of Geriatric Psychiatry, 7, 235-243.

Unützer, J., Katon, W., Sullivan, M. and Miranda, J. (1999b). Treating depressed older adults in primary care: narrowing the gap between efficacy and effectiveness. Milbank Quarterly, 77, 257-274.

Unützer, J., Patrick, D. L., Diehr, P., Simon, G., Grembowski, D. and Katon, W. (2000). Quality adjusted life years in older adults with depressive symptoms and chronic medical disorders. International Psychogeriatrics, 12, 15-33.

Unützer, J. et al. (2002). Collaborative care management of late-life depression in the primary care setting: a randomized controlled trial. $\mathcal{f A} M A, 288,2836-2845$.

Unützer, J. et al. (2008a). Long-term cost effects of collaborative care for late-life depression. American fournal of Management Care, 14, 91-96.

Unützer, J. et al. (2008b). Care management for depression and osteoarthritis pain in older primary care patients: a pilot study. International fournal of Geriatric Psychiatry, 23, 1166-1171.

Wells, K. B. et al. (1989). The functioning and well-being of depressed patients: results from the Medical Outcomes Study. $\mathscr{f} A M A, 262,914-919$. 